\title{
Validation and reliability of the Baecke questionnaire for the evaluation of habitual physical activity in adult men*
}

\author{
Alex Antonio Florindo ${ }^{1}$ and Maria do Rosario Dias de Oliveira Latorre ${ }^{1}$
}

\begin{abstract}
The aim of this study was to verify validity and reliability of the scores for physical exercise in leisure (PEL), leisure and locomotion activities (LLA), and total score (TS) of the Baecke habitual physical activity questionnaire in adult males. Twenty-one students of Physical Education were evaluated. For validation, the maximum oxygen uptake ( $\left.\mathrm{V}_{2} \max \right)$ and the decrease of the heart rate in percentile (\%DHR) were measured through the Cooper's 12-minute walk or run test, and an annual index of physical exercise (IPE), and a week index of locomotion activities (ILA). The reliability was verified through test-retest with interval of 45 days. The Pearson correlation coefficient, and partial correlation adjusted for age and body mass index were used for validation. The intraclass correlation and paired $t$-test were used for reliability. The results indicated that \%DHR was correlated with LLA and TS $(r=0.47$ and $p=0.030 ; r=$ 0.48 and $p=0.027$, respectively). IPE was correlated with PEL and TS $(r=0.56$ and $p=0.008 ; r=0.46$ and $p=0.036$, respectively). ILA was correlated with LLA and TS $(r=0.64$ and $p=0.002$ and $r=0.51$ and $p=0.017$, respectively). There was no significant difference in PEL, LLA and TS means in test-retest. The intraclass correlations were $r=$ $0.69 ; \mathrm{r}=0.80$ and $\mathrm{r}=0.77$, respectively for PEL, LLA and TS. In conclusion, the Baecke questionnaire is valid and
\end{abstract}

\footnotetext{
* Apoio através de bolsa de doutorado da Fapesp para Alex Antonio Florindo.

1. Departamento de Epidemiologia da Faculdade de Saúde Pública da Universidade de São Paulo.

Received in 6/12/02

$2^{\text {nd }}$ version received in $16 / 2 / 03$

Accepted in 20/4/03
}

Correspondance address:

Alex Antonio Florindo

Departamento de Epidemiologia, Faculdade de Saúde Pública,

Universidade de São Paulo

Av. Dr. Arnaldo, 715

01246-904 - São Paulo, SP

Tel.: +55(11) 3066-7744, fax: +55(11) 3082-2920

E-mail: aflorind@usp.br reliable to measure habitual physical activity in Brazilian adult men.

Key words: Habitual physical activity. Evaluation. Questionnaire. Men.

\section{INTRODUCTION}

There are different methods to assess habitual physical activity (HPA), being the questionnaires the most accessible for epidemiologic studies ${ }^{1}$. Different questionnaires presented in the literature were summarized in a 1997 supplement $^{2}$. However, for the Brazilian population, there are few validated instruments. Another problem is related to the validation standards. There is not yet a golden standard to measure physical activity or fitness against HPA questionnaires. Methods such as energy exertion measured by doubly labelled water, or motion sensors such as accelerometers are being used in validation studies. The first method, however, is quite expensive and difficult to apply. The second is more feasible in terms of costs, but its application and control of participants are difficult to do, particularly in developing countries, such as Brazil, as they demand high compliance level from participants in using, handling and giving the devices back. Inquiries on energy exertion have been an alternative for measuring physical activity, as the subjects need to record their physical activities over a pre-defined period of time only. Also as alternatives, physical fitness measures have been used, as they require only attendance of the subject at the lab or field to carry out the test. Baecke's questionnaire for $\mathrm{HPA}^{3}$ is a recording tool for the past 12 months, easy to understand and apply, and measures qualitative and quantitative indices, addressing dimensions such as occupational physical activity, physical exercises in leisure, and leisure and locomotion activities. This instrument has been used in an epidemiologic study of the Brazilian population ${ }^{4}$. The purpose of this study was to investigate validity and reliability of the scores from physical exercises in leisure, and leisure and locomotion activities assessed by Baecke's habitual physical activity questionnaire for Brazilian adult males. 


\section{METHODS}

\section{Subjects}

The studied population included male students attending the sixth semester of the Physical Education School of the Escola da Polícia Militar do Estado de São Paulo (EEFPMSP), and data collection was carried out between August and September, 2001. From a total of 26 students enrolled, two were excluded for impossibility of physical activity assessment, and three for not completing all the tests, remaining 21 students to be evaluated.

The calculation of the size of the sample was carried out assuming a 0.50 correlation as the average result of the correlation coefficients of studies relating total Baecke's HPA scores with maximum oxygen uptake ${ }^{5-7}$, employing a type I $(\alpha)$ error of $5 \%$, and a type II ( $\beta$ ) error of $20 \%$, in accordance with Browner et al. (2001) ${ }^{8}$. This study was part of a broad Ph.D. program research approved by the Ethics Committee of the Public Health School from the Universidade de São Paulo.

\section{Habitual physical activity questionnaire}

Baecke's questionnaire includes 16 questions comprehending three HPA scores from the past 12 months: 1) occupational physical activities score (8 questions); 2) physical exercises in leisure (PEL) score (4 questions); 3) leisure

\begin{tabular}{|c|c|c|c|c|c|}
\hline \multicolumn{6}{|l|}{$\begin{array}{l}\text { FIGURE } 1 \\
\text { Habitual physical activity questionnaire }\end{array}$} \\
\hline \multirow{2}{*}{$\begin{array}{l}\text { Please, make a circle around the appropriate answer for each question, considering the past } \\
12 \text { months: } \\
\text { 1. Do you or did you practice sports or physical exercise within the past } 12 \text { months: } \\
\text { yes/no } \\
\text { Which sport or physical exercise do you or did you practice more often? }\end{array}$} & & & & & \\
\hline & & & & & \\
\hline - how many hours a week? & & & & & \\
\hline - how many months a year? & & & & & \\
\hline If you practice or practiced a second modality of sport or physical activity, what is it?: & & & & & \\
\hline - how many hours a week? & & & & & \\
\hline - how many months a year? & & & & & \\
\hline $\begin{array}{l}\text { 2. When compared to others of my age, I think my physical activity during leisure hours is: } \\
\text { much more/more/the same/less/much less }\end{array}$ & 5 & 4 & 3 & 2 & 1 \\
\hline $\begin{array}{l}\text { 3. During leisure hours, I sweat: } \\
\text { very often/often/sometimes/seldom/never }\end{array}$ & 5 & 4 & 3 & 2 & 1 \\
\hline $\begin{array}{l}\text { 4. During leisure hours, I practice sports or physical exercises: } \\
\text { never/seldom/sometimes/often/very often }\end{array}$ & 1 & 2 & 3 & 4 & 5 \\
\hline $\begin{array}{l}\text { 5. During leisure time, I watch TV: } \\
\text { never/seldom/sometimes/often/very often }\end{array}$ & 1 & 2 & 3 & 4 & 5 \\
\hline $\begin{array}{l}\text { 6. During leisure hours, I walk: } \\
\text { never/seldom/sometimes/often/very often }\end{array}$ & 1 & 2 & 3 & 4 & 5 \\
\hline $\begin{array}{l}\text { 7. During leisure hours I ride a bike: } \\
\text { never/seldom/sometimes/often/very often }\end{array}$ & 1 & 2 & 3 & 4 & 5 \\
\hline $\begin{array}{l}\text { 8. For how many minutes a day do you walk or ride a bike going back and forth from work, } \\
\text { school or shopping? } \\
<5 / 5-15 / 16-30 / 31-45 />45\end{array}$ & 1 & 2 & 3 & 4 & 5 \\
\hline & \multicolumn{2}{|c|}{ Total in minutes } & & & \\
\hline
\end{tabular}


and locomotion physical activities (LLA) score (4 questions). In this investigation, as the subjects were students, the PEL and LLA scores were used, the total score being the sum of these (TS = PEL + LLA). The questionnaire with PEL and LLA scores, and their calculation formulas are in figures 1 and 2, respectively.

\section{Methodology}

The sixth semester class of the course was selected, because of the facility in applying the assessment tests, as they were taking practical, field classes. The first approach was done in the classroom. First, the person responsible for the investigation explained the purposes of the study, and all those who agreed to take part signed the informed consent form. After this step, two questionnaires were handed out, one on demographics and the HPA questionnaire. The students were asked to call the person in charge of the investigation if they had any questions to ask, without leav- ing their seats. The average response time for the HPA questionnaire was 5 minutes. Once all students completed the questionnaire, they were taken to the athletic track for physical assessment.

\section{Criteria validity}

To check cardiorespiratory capacity, Cooper's 12-minute walk or run test was used ${ }^{9}$. The test was carried out in EEFPMSP's official athletic track. Based on the total distance attained, maximum oxygen intake ( $\left.\dot{\mathrm{VO}}_{2} \max \right)$ was measured, in milliliter per kilo of body weight per minute $(\mathrm{ml} / \mathrm{kg} /$ $\mathrm{min}$ ), in accordance with the formula proposed by Cooper and described by Leite ${ }^{10}$ :

VंO ${ }_{2} \operatorname{máx}(\mathrm{ml} / \mathrm{kg} / \mathrm{min})=($ distance attained in meters -504$) / 45$

Final heart rate $\left(\mathrm{HR}_{\text {final }}\right)$ was assessed immediately after the test, and recovery heart rate $\left(\mathrm{HR}_{\text {recovery }}\right)$ was assessed

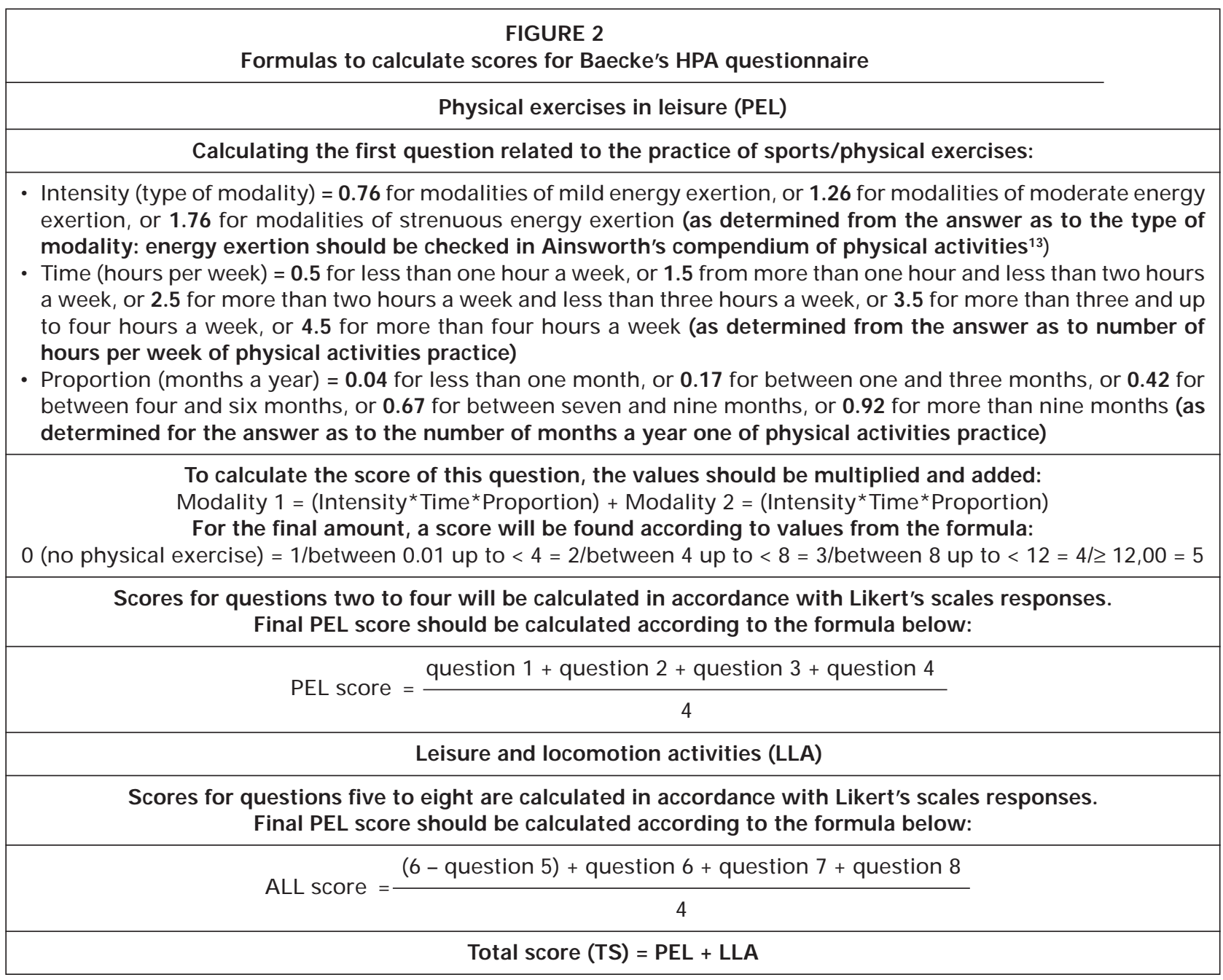


one minute after the test, through Polar ${ }^{\circledR}$ monitors models Beat and Favor. The percentile for decrease of heart rate (\%DHR) was calculated through the formula adapted from Oliveira et al. ${ }^{11}$ and used by Florindo ${ }^{12}$ :

$$
\% D H R=\left(H R_{\text {final }}-H R_{\text {recovery }}\right) * 100 / H R_{\text {final }}
$$

\section{Concurrent validity}

To assess concurrent validity, a record of physical exercise over the past 12 months was used. Detailed questions on the practice of physical exercise in terms of frequency in months per year, and duration in hours per week were asked for the two main modalities. The intensity of the modalities in mets was determined in accordance with Ainsworth et al.'s compendium of physical activities ${ }^{13}$. A total index of physical exercises (IPE) was calculated for the previous 12 months in kilocalories per year (kcal/year) according to a model proposed by Kriska ${ }^{2}$ :

FREQUENCY (months/year)*DURATION (hours/month)* INTENSITY (mets hours/year)*WEIGHT $(\mathrm{kg})$

\section{$\downarrow$}

INDEX OF PHYSICAL EXERCISES (use of energy in kcal/year)

The question about locomotion activities from the questionnaire (the last question) was transformed in the index of locomotion activities (ILA), measured in kcal, by multiplying the total number of hours per week walking or riding a bike to go to and come back from work, school, shopping by the average mets of these two activities as determined in the compendium of physical activities ${ }^{13}$ and weight:
DURATION (hours/week)*INTENSITY (mets hours/week)*WEIGHT (kg)

$\downarrow$

INDEX OF LOCOMOTION ACTIVITIES

(use of energy in $\mathrm{kcal} / \mathrm{week}$ )

\section{Reliability}

After 45 days, the measurement was repeated (retest) according to the criteria used in the first measurement.

\section{Statistical analysis}

Validation analysis used the Pearson correlation coefficient, and age- and body mass index (BMI) adjusted coefficient between HPA and $\dot{\mathrm{VO}}_{2} \max$, IPE and ILA scores, after checking that data had normal distribution through the Kolmogorov-Smirnov test.

For reliability analysis, the intraclass correlation test and $t$-paired test were used.

For all analyses, a significance level of $\mathrm{p}<0.05$ was used. All calculations were done with the software Statistical Package for the Social Sciences (SPSS) version 10.0.

\section{RESULTS}

Table 1 presents the features of the sample. Age ranged from 27 to 37 years, mean of 32.6 years ( $\mathrm{sd}=3.2$ years). Weight ranged from normal to overweight with no obese student. $\dot{\mathrm{V}}_{2} \max$ had a high average rate, showing the good cardiorespiratory capacity of the subjects. It was noted that the average annual energy exertion on physical exercises within the sample was high, however, with significant vari-

TABLE 1

Descriptive statistics of the study' subjects variables

Variables

Age (years)

Body mass index $\left(\mathrm{kg} / \mathrm{m}^{2}\right)$

Leisure physical exercises score

Leisure and locomotion activities

Total score

Maximum oxygen intake $(\mathrm{ml} / \mathrm{kg} / \mathrm{min})$

Distance completed in Cooper's test (meters)

Physical exercises rate (kcal/annual)

Locomotion activities rate (kcal/weekly)

Final heart rate (bpm)

Recovery heart rate (bpm)

Percentage of heart rate decrease
Males $(\mathbf{N}=\mathbf{2 1})$

\begin{tabular}{cc}
\hline Minimum-maximum & Average (sd) \\
$27-37$ & $32.6(3.1)$ \\
$19.7-27.7$ & $23.5(2.2)$ \\
$2,750-4,500$ & $4,002(0.464)$ \\
$2,250-4,250$ & $3,417(0.526)$ \\
$5,000-8,750$ & $7,429(0.881)$ \\
$45.5-62.1$ & $55.4(4.1)$ \\
$2,550-3,300$ & $2,999.0(185.8)$ \\
$35,280.0-430,080.0$ & $196,016.4(115,023.6)$ \\
$96.0-5,085.0$ & $1,386.4(1,139.4)$ \\
$154-198$ & $181(11)$ \\
$122-177$ & $150(15)$ \\
$7.0-30.0$ & $16.9(6.0)$ \\
\hline
\end{tabular}


ations among the subjects. The weekly energy exertion in locomotion activities was relatively low, but also showed important variations.

It has been noted that PEL and TS scores were correlated to IPE, and correlation improved after adjusted for age and BMI (table 2). LLA and TS scores were correlated to ILA, and correlation improved for LLA after age and BMI adjustments, and maintained on TS evaluation. There was no significant correlation among the PEL, LLA and TS scores with $\dot{\mathrm{VO}}_{2} \max$. As for \%DHR, a significant correlation with LLA and TS was noted, which improved for LLA after age and BMI adjustments, and was maintained for TS.

In regard to reliability measures (table 3 ), it was noted that intraclass correlation coefficients were significant for all HPA scores, being the highest values found, respectively, in TS, LLA and PEL scores. There were no significant differences between the average of the first and second measurements for all HPA scores.

\section{DISCUSSION}

In this study, physical activity (IPE and ILA) and physical fitness ( $\mathrm{V}_{2} \max$ and \%DHR) standards were compared to Baecke's HPA questionnaire scores.

$\dot{\mathrm{V}}_{2}$ max is related to energy exertion, and is chiefly influenced by age ${ }^{14}$ and physical fitness level. In this study, no HPA score was significantly correlated with $\dot{\mathrm{V}}_{2}$ max. Significant results were found in the correlation of physical exercises score with peak $\dot{\mathrm{V}}_{2}(\mathrm{r}=0.47)$ among Belgian adult males ${ }^{5}$, and with $\dot{\mathrm{V}} \mathrm{O}_{2} \max (\mathrm{r}=0.52)$ in American male and female adults 7 . In the analysis of modified Baecke's questionnaire, correlation values of 0.45 for American females and 0.67 for American males were obtained ${ }^{15}$. It is believed that significant correlation values were not obtained in this study due to the homogeneity of $\mathrm{V}_{2}$ max values (sample of EEFPMSP Physical Education students), as the average value from the group was high, with little variation, which impaired the analysis.

TABLE 2

Pearson correlation coefficient and adjusted coefficients between HPA scores and physical fitness and physical activity standards

\begin{tabular}{|c|c|c|c|}
\hline Measurements & $\begin{array}{l}\text { PEL } \\
\text { r(p) }\end{array}$ & $\begin{array}{l}\text { LLA } \\
\text { r(p) }\end{array}$ & $\begin{array}{l}\text { TS } \\
\text { r(p) }\end{array}$ \\
\hline \multicolumn{4}{|l|}{ Simple correlation } \\
\hline $\begin{array}{l}\dot{\mathrm{V}} \mathrm{O}_{2} \text { máx }(\mathrm{ml} / \mathrm{kg} / \mathrm{min}) \\
\% \mathrm{DHR} \\
\text { IPE (kcal/year) } \\
\text { ILA (kcal/week) }\end{array}$ & $\begin{array}{l}0.04(0.867) \\
0.38(0.091) \\
\mathbf{0 . 5 6}(\mathbf{0 . 0 0 8 ) *} \\
0.25(0.264)\end{array}$ & $\begin{array}{l}0.24(0.285) \\
\mathbf{0 . 4 7}(0.030)^{*} \\
0.28(0.224) \\
\mathbf{0 . 6 4}(\mathbf{0 . 0 0 2})^{*}\end{array}$ & $\begin{array}{l}0.17(0.470) \\
0.48(0.027)^{*} \\
0.46(0.036)^{*} \\
0.51(0.017)^{*}\end{array}$ \\
\hline \multicolumn{4}{|c|}{ Age and BMI adjusted correlation } \\
\hline $\begin{array}{l}\mathrm{VO}_{2} \max (\mathrm{ml} / \mathrm{kg} / \mathrm{min}) \\
\% \mathrm{DHR} \\
\text { IPE (kcal/annual) } \\
\text { ILA (kcal/weekly) }\end{array}$ & $\begin{array}{l}0.15(0.539) \\
0.32(0.172) \\
\mathbf{0 . 6 1}(\mathbf{0 . 0 0 5})^{*} \\
0.22(0.355)\end{array}$ & $\begin{array}{l}0.42(0.069) \\
\mathbf{0 . 5 1}(\mathbf{0 . 0 2 6})^{*} \\
0.25(0.292) \\
\mathbf{0 . 6 9}(\mathbf{0 . 0 0 1})^{*}\end{array}$ & $\begin{array}{l}0.33(0.169) \\
0.47(0.043)^{*} \\
0.47(0.043)^{*} \\
0.52(0.022)^{*}\end{array}$ \\
\hline
\end{tabular}

* $p<0,05$; PEL (physical exercises in leisure score); LLA (leisure and locomotion activities); TS (total score); \%DHR (percentage of heart rate decrease); IPE (physical exercises index); ILA (index of locomotion activities).

TABLE 3

Paired ttest and intraclass correlation coefficients significance values for repeated measurements

\begin{tabular}{|c|c|c|c|c|}
\hline Scores & $\begin{array}{l}\text { Measurement } 1 \\
\text { average (sd) }\end{array}$ & $\begin{array}{l}\text { Measurement } 2 \\
\text { average (sd) }\end{array}$ & $\begin{array}{c}t \text { test } \\
P\end{array}$ & $\begin{array}{c}\text { Intraclass correlation } \\
\text { r (IC) }\end{array}$ \\
\hline PEL & $4,011(0.464)$ & $3,952(0.640)$ & 0.542 & $0.69(0.40-0.86)^{*}$ \\
\hline LLA & 3,417 (0.526) & 3,440 (0.713) & 0.797 & 0.80 (0.57-0.91)* \\
\hline TS & $7,429(0.881)$ & 7,393 (1.286) & 0.832 & $0.77(0.52-0.90)^{*}$ \\
\hline
\end{tabular}


It is to be stressed the magnitude of correlation values obtained from each score. One believes that, being a physical fitness measurement, $\mathrm{V}_{2}$ max better differentiates physical exercises from other physical activities. However, according to the results of this study, higher values were obtained in comparing leisure and locomotion activities. Other investigations have found lower correlation between leisure and locomotion activities score and $\dot{\mathrm{V}}_{2} \max ^{5,7}$.

Baecke's questionnaire includes comparison and selfassessment questions. There can be some difficulties for answering the questions ${ }^{16}$. Due to the importance of questions addressing sweating or perspiration for HPA assessment ${ }^{16,17}$, correlation between the gross value from selfassessment on sweating with $\dot{\mathrm{V}}_{2}$ max was tested. There was positive correlation after age and BMI adjustment $(\mathrm{r}=0.51$; $p=0.027$ ) (data not shown). These results are similar to those found in the analysis of the perspiration report by correlating Paffenbarger's questionnaire total score with $\dot{\mathrm{V}}_{2} \max (\mathrm{r}=0.54)$ in adult and elder American males ${ }^{16}$.

Heart rate and its recovery processes are considered physical fitness indicators ${ }^{11}$. The \%DHR index is correlated to $\dot{\mathrm{VO}}_{2} \max ^{12}$. In this study, once more an interesting result has been found, with significant correlation between \%DHR and HPA scores, underlining the highest magnitude obtained with leisure and locomotion activities. Using the workload from a maximum treadmill test as an indicator, Jacobs et al. $(1993)^{7}$ showed significant correlation with physical exercises score $(r=0.57)$ and total score $(r=0.51)$, and finally with leisure and locomotion score $(r=0.33)$. Other studies using the Minnesota questionnaire reached significant correlation on the assessment of the total score and submaximal heart rate in male American adults $(r=0.59)^{16}$, and in American males and females as a group $(\mathrm{r}=0.45)^{7}$.

There was significant correlation between energy exertion measured by IPE and the physical exercises score, which remained constant even after adjusted for age and BMI. The standard used in this study was a detailed recording of physical exercises over the past 12 months. This means that the standard reflects this type of physical activity within the past year. It is to be noted that literature data are controversial as to the magnitude of the correlation of this score with the recorded data and with other comparative standards. In the analysis of daily energy exertion, an index of $r=0.58$ from physical exercises score in American adult males ${ }^{15}$, and $\mathrm{r}=0.51$ from total score in Dutch elderly females were obtained $^{18}$. As to other standard measurements, such the use of an accelerometer, values of $r=0.34$ from physical exercises score in Belgian adult males ${ }^{5}$, and $\mathrm{r}=0.34$ with physical exercises score in American adult males ${ }^{15}$ were obtained. With doubly labeled water, $r=0.46$ was obtained from the correlation with the physical exercises score in
Belgian adult males ${ }^{19}$. In this population a physical activity index was calculated based on energy exertion divided by metabolic rate in hours of sleep, and a correlation of $r=$ 0.55 was obtained from the physical exercises score ${ }^{19}$.

A significant correlation between ILA-measured energy exertion and leisure and locomotion physical activities score was found. Also significant correlations between the daily energy exertion and the leisure and locomotion activities were also found for American females $(r=0.42)$ and males $(\mathrm{r}=0.37)^{15}$, and with the total score for Dutch females $(\mathrm{r}=$ $0.52)^{6}$. In comparing with the accelerometer, a correlation of $r=0.28^{5}$ with the leisure and locomotion activities score in Belgian adult males was found; and with doubly labeled water, the correlation was $r=0.50^{19}$.

A number of studies have shown good reliability indices for Baecke's HPA questionnaire. The values for physical exercises score were of $\mathrm{r}=0.92$ and $\mathrm{r}=0.88$ respectively, for American females and males ${ }^{15}$, and $\mathrm{r}=0.93$ for Belgian adult males ${ }^{20}$. The total score follows the other indices, reaching correlation values of $\mathrm{r}=0.93$ for adult American males and females ${ }^{7}$, and $\mathrm{r}=0.86$ for Belgian adult males ${ }^{20}$. Values assessed with a 15-day interval did not present major changes, as shown in Belgian adult males, being of $r=$ 0.79 for physical exercises ${ }^{19}$. In the analysis of leisure and locomotion physical activities score, with a 30-day interval, high correlation values were obtained from American females and males $(r=0.87 \text { and } r=0.86 \text {, respectively })^{15}$, and from Belgian adult males $(r=0,87)^{20}$. With a 15-day interval, values of $r=0.66$ were obtained from Belgian males ${ }^{19}$. In the analysis of longer intervals, such as between five and 11 months, coefficients of $r=0.88$ and $r=0.81$ were obtained for PEL, and $\mathrm{r}=0.76$ and $\mathrm{r}=0.71$ for LLA in Dutch adults and elders, respectively ${ }^{18}$. Such reliability results from Baecke's HPA scores are similar to those found for the population of the present study.

\section{CONCLUSION}

From the results shown for the population of the present study, and from comparison with results of studies from developed countries, on concludes that Baecke's HPA questionnaire is a good option to assess habitual physical activities in Brazilian adult males.

\section{ACKNOWLEDGMENTS}

To the Fundação de Amparo à Pesquisa do Estado de São Paulo (FAPESP) for the Ph. D. scholarship grant given to Alex Antonio Florindo (process \# 00/09482-8), and to Conselho Nacional de Pesquisas $(\mathrm{CNPq})$ for the scholarship grant given to Maria do Rosario Dias de Oliveira Latorre. To Professor Raul Santo, for helping access to the Physical Education School of the Escola da 
Polícia Militar, and to Professor Paulo Merino for his help in applying the instruments.

All the authors declared there is not any potential conflict of interests regarding this article.

\section{REFERENCES}

1. Paffenbarger Jr RS, Blair SN, Lee IM, Hyde RT. Measurement of physical activity to assess health effects in free-living populations. Med Sci Sports Exerc 1993;25:60-70.

2. Pereira MA, Fitzgerald SJ, Gregg EW, Joswiak ML, Ryan WJ, Suminski RR, et al. A collection of physical activity for health related research. Med Sci Sports Exerc 1997;29:S1-205.

3. Baecke JA, Burema J, Frijters JE. A short questionnaire for the measurement of habitual physical activity in epidemiological studies. Am J Clin Nutr 1982;36:936-42.

4. Florindo AA, Latorre MRDO, Jaime PC, Tanaka T, Pippa MGB, Zerbini CA. Past and present habitual physical activity and its relationship with bone mineral density in men aged 50 years or older in Brazil. J Gerontol A Biol Sci Med Sci 2002;57:M654-7.

5. Phillippaerts RM, Westerterp KR, Lefevre J. Comparison of two questionnaires with a tri-axial accelerometer to assess physical activity patterns. Int J Sports Med 2001;22:34-9.

6. Pols MA, Peeters PHM, Kemper HCG, Collette HJA. Repeatability and relative validity of two physical activity questionnaires in elderly women. Med Sci Sports Exerc 1996;28:1020-5.

7. Jacobs Jr DR, Ainswoth BE, Hartman TJ, Leon AS. A simultaneous evaluation of 10 commonly used physical activity questionnaires. Med Sci Sports Exerc 1993;25:81-91.

8. Browner WS, Newman TB, Cummings SR, Hulley SB. Estimating sample size and power: the nity-gritty. In: Hulley SB, Cummings SR, Browner WS, Grady D, Hearst N, Newman TB, editors. Designing clinical re- search: an epidemiologic approach. $2^{\text {nd }}$ ed. Baltimore: Ed. Williams \& Wilkins, 2001;65-91.

9. Cooper KH. A means of assessing maximal oxygen intake. JAMA 1968; 203:201-4.

10. Leite PF. Fisiologia do exercício: ergometria, condicionamento físico e cardiologia desportiva. 4a ed. São Paulo: Robe Editorial, 2000.

11. Oliveira FR, Silva AS, Araujo AS, Costa RF, Colantonio E, Kiss MAPDM. Cinética da recuperação da frequiência cardíaca como indicador de capacidade aeróbica em corredores. Jornal Informativo da FIEP 1994;2:8

12. Florindo AA. O percentual de decréscimo da freqüência cardíaca como indicador da aptidão aeróbia. Anais do I Simpósio Fitness Brasil, Santos, SP, 1997; 15 .

13. Ainsworth BE, Haskell WL, Whitt MC, Irwin ML, Swartz AM, Strath SJ, et al. Compendium of physical activities: an update of activity codes and MET intensities. Med Sci Sports Exerc 2000;32:S498-504.

14. Berthouze SE, Minaire PM, Castells J, Busso T, Vico L, Lacour JR. Relationship between mean habitual daily energy expenditure and maximal oxygen uptake. Med Sci Sports Exerc 1995;27:1170-9.

15. Richardson MT, Ainsworth BE, Wu HC, Jacobs Jr DR, Leon AS. Ability of the atherosclerosis risk in communities (ARIC)/Baecke questionnaire to assess leisure-time physical activity. Int J Epidemiol 1995;24:685-93.

16. Siconolfi SF, Lasater TM, Snow RCK, Carleton RA. Self-reported physical activity compared with maximal oxygen uptake. Am J Epidemiol 1985; $122: 101-5$

17. Leon AS, Jacobs Jr DR, DeBacker G, Taylor HL. Relationship of physical characteristics and life habits to treadmill exercise capacity. Am J Epidemiol 1981;113:653-60.

18. Pols MA, Peeters PHM, Bueno-de-Mesquita HB, Ocké MC, Wentink CA, Kemper HCG, et al. Validity and repeatability of a modified Baecke questionnaire on physical activity. Int J Epidemiol 1995;24:381-8.

19. Phillippaerts RM, Westerterp KR, Lefevre J. Doubly labelled water validation of three physical activity questionnaires. Int J Sports Med 1999; 20:284-9.

20. Phillippaerts RM, Lefevre J. Reliability and validity of three physical activity questionnaires in Flemish males. Am J Epidemiol 1998;147:98290. 